\title{
Discussion on Computer-Assisted Mandarin Level Test in Colleges
}

\author{
Hanqing Zhou ${ }^{1,}$, Ling Huang ${ }^{2, b}$ \\ ${ }^{1}$ Archives, Jiangxi Science \& Technology Normal University, Nanchang, China \\ ${ }^{2}$ Basic Teaching Department, Jiangxi College of Foreign Studies, Nanchang, China \\ azhouhq123456789@163.com; bhuangling0828@163.com
}

Keywords: computer; mandarin level test; problem; countermeasure.

\begin{abstract}
With rapid development and extensive application of computer technology, Mandarin level test also grows rapidly and changes from the traditional manual test to computer-assisted test. Now, all the colleges carry out the Mandarin level test through the computer and have achieved good results. However, it still exists some problems in the process. The paper analyzes the problems and puts forwards corresponding countermeasures.
\end{abstract}

\section{Introduction}

With rapid development and extensive application of computer technology, Mandarin level test also grows rapidly and changes from the traditional manual test to computer-assisted test. Now, all the colleges carry out the Mandarin level test through the computer and have achieved good results. However, it still exists some problems in the process. The paper analyzes the problems and puts forwards corresponding countermeasures.

\section{Advantages of computer-assisted Mandarin level testing}

Although so far, the testing scale of computer-assisted mandarin level test cannot be mentioned in the same breath with the manual test, it is a revolutionary breakthrough and is the inevitable trend of more scientific and standardized development of mandarin level test. The advantages brought are obvious.

The evaluation carried out by the machines is more accurate, objective and stable. Firstly, the test system software identified and recognized by the National Language Committee is implemented in accordance with the requirements of the syllabus from choosing the item pool to the evaluation system, and promoted in all the regions of the country. The scoring scale is truly unified nationally. Secondly, due to the characteristics of the machine, large errors won't occur because of the fluctuation of physical and psychological factors, no matter how many times tested. Thirdly, put an end to the human score to further guarantee the reliability of the test.

In the long run, the computer-assisted Mandarin level test will reduce the testing cost greatly and improve the working efficiency and flexibility. (1) The computer-assisted Mandarin level test is basically paperless test, so the pre-preparation job is relatively reduced. (2) In manual test, hiring testers, arranging examination, implementing the staff and other series of examination management work is also very large: the preparation cycle is relatively long; the cost of transportation, meals and testing service fee is not a small expenditure. After the implementation of machine test, the scene only needs a small number of staff, saving manpower and material resources.

Making full use of modern technology to promote mandarin, which is in line with the development requirement of creating the Mandarin level test into bright national brand. (1) The Mandarin level test involves a wide range and has great social significance. The State Language Commission set up the research plan on the application of language and proposed to pay attention to the problem of "means modernization". That is to say, we should make use of the computer, the internet and related modern equipment to achieve the modernization of Mandarin level test from management, testing, and training to research, even to become the famous national brand. (2)From the point of development in 
recent years, the management works in Mandarin level test, such as, managing the testers and subordinate test station, all make full use of the computer technology. And one important part of the test is difficult to score automatically due to the difficulty of the speech processing technology. The computer-assisted Mandarin level test implemented now is good remedy for this weak link.

\section{Problems existing in the computer-assisted Mandarin level test in colleges}

The related function of the test system remains to be improved. Mandarin level test system is not stable and the sensitivity of detection tools is not enough. The compatibility of the test system is not strong to the hardware and software. For example, the same type or batch computer system can pass the environment detection, but may be not stable in some machines while stable in other machines.

The relevant rules and regulations of computer-assisted Mandarin level test are not perfect. After the computer-assisted Mandarin level test rooms are established, the related notes and instructions, examinee operation flow, and the management system should be set up one by one. And the governing body, registration organization, examination management, performance management, test monitoring and so on should be established the matched system or process. At present, the management system of Mandarin level test in colleges is not perfect, so problems often occur in actual operation, such as, ignoring the exam training will make the students not familiar with the related test rules and requirements and lead them to fail the audition; imperfect examination monitoring system or process may lead to serious violation of discipline. Therefore, establishing sound system is imperative.

The professional level of management staff is not enough. In manual testing, as long as be familiar with the operation process, the staff can organize and supervise the Mandarin level test and other related work. However, computer-assisted test put forwards higher requirements to the management personnel. They not only need to master computer hardware and software and Mandarin level testing system function flow, but also need to be familiar with the routine management of the test. At the same time, their level of mandarin also needs to reach corresponding grade. However, in actual operation, their professional level is uneven due to many reasons. Some are not major in the computer; some is low in mandarin level although having certain computer foundation, especially the older is particularly prominent.

The management of the Mandarin level testing computer room is not in place. The Mandarin level testing computer room, an important place for testing, is the premise to realize computer-assisted Mandarin level test. Therefore, strengthening the management of the testing computer room is very important. At present, the management of testing lab equipment's is not in place, and the rules and regulations of testing lab operation has not been established, which cannot guarantee the long-tern normal operation of the test system. In addition, the security management of the testing room, such as, anti-theft and fire control, has not caused the attention of the concerned departments.

\section{Countermeasures for the problems existing in the computer-assisted Mandarin level test in colleges}

Optimize the relevant functions of the test software. In order to make the computer-assisted test system serves the management work of mandarin level test better, the software must be optimized continuously, which is the foundation to future promote Mandarin level test. Mandarin level test system should be led by the State Department and jointly researched and developed by all top experts and research institutions, and modern Chinese speech experts, especially those are very familiar with the computer technology and the mandarin theory.

Improve the management system. It is not only the premise to ensure the scientific development of the testing work, but also the means to ensure the management and the optimization work. So, before carrying out the Mandarin level testing work, a series of rules and regulations should be set up to standardize the testing work, such as "Mandarin level testing norms", "the working regulations of Mandarin level test station", etc. In daily work, the colleges can improve the management system 
constantly by drawing on work experience or learning advanced management experience from the brother schools. Through the perfect management system and regulations, propose strict request to the related personnel of the test work to guarantee the effective completion of the test work.

Strengthen the process management of the test. The process of Mandarin level test is serious and the key, so the staff should pay more attention to process management to create good test environment for students and guarantee the test process public, impartial, and fair. Before testing, check all kinds of testing tool carefully, especially the stability of the power, the computer and related components. At the same time, the testing software should also be ensured normally. In the process of testing, strictly prohibit the entry and exit of unrelated persons, and emphasize the examination discipline. Outside the test station, the colleges should set work station to explain the examination notes to the test personnel and arrange them to enter examination room orderly. In addition, in order to prevent accidents in the process of testing, arrange emergency personnel to ensure the normal use of the hardware equipment's.

Combine mandarin training with teaching. Mandarin training is not reactive overnight, and the colleges should add mandarin training contents appropriately in the usual teaching to help students learn and master mandarin skills. Some colleges, opening Chinese language and literature, should make effective use of the professional teachers to carry out the study of linguistics and phonetics courses in teachers and students, and bring the mandarin work into daily teaching plan through the Chinese course, so as to improve the Mandarin level of all teachers and students in teaching practice.

Do remedial work to ensure the test work completed successfully. In Mandarin level test, the management of rehabilitation work is also very important. Such as, the maintenance of the equipment's, the record and preservation of the machines test, the upload, entry and publication of the results, certification issuance and so on are needed to achieve orderly management. Mandarin level testing management station should establish perfect rehabilitation work flow, clear the division of labor, and implement accountability system. After the completion of the test, the staff should summarize the problems in time and draw lessons from experience to work better from now on.

Strengthen the scientific management of the testing computer room. The testing computer room is an important venue for the Mandarin level test. In order to ensure the smooth progress of the Mandarin level test, we must strengthen the management and maintenance of the testing computer room. First of all, the management staff must guarantee the normal operation of hardware and software; second, the management personnel should always pay attention to whether the entrance is smooth and prevent unexpected things, such as the occurrence of earthquake and fire, so as to ensure the escape channel is flow. And cooperate with relevant departments to do well in the network information security management of the testing room to ensure the completion of Mandarin level test as scheduled.

\section{Summary}

The application of computer-assisted Mandarin level test makes the test enter into a more scientific and standard age, and is a historic leap. We should grasp the opportunity to strengthen the teaching reform and improve the efficiency and quality of Mandarin level test.

\section{References}

[1]Qifeng Song, Jin Yang. The management and development of Mandarintest station in higher vocational colleges $[\mathrm{J}]$. The management and technology of small and medium-sized enterprises, 2010(09)

[2]Hui $\mathrm{Wu}$. The way of improving the management effectiveness of the Mandarintest station in university[J]. China Science and Education Innovation Heraid, 2013(32).

[3] Douglas, D. Assessing Languages for specific purposes [M]. New York: Cambridge University Press, 2000. 
[4]Loumi, S. Assessing speaking[M].New York: Cambridge University Press,2004.

[5]Roever,C. Web-based language testing[J]. Language Learning \& Technology,2001,5(2),84-94.

[6]Qian Huang. The problems and countermeasures of computer-assisted mandarin level test[J]. Journal of Langfang Normal University (Natural science edition), 2011,11(4): 122-124.

[7]Weibin Long, Caihua Chen. The analysis of the status of the computer-assisted mandarin level test[J]. Journal of Xihua University ( philosophy and social science edition), 2013, 32(2): 43-45.

[8]Fulcher G. Practical Language Testing[M]. London: Hodder Education, 2010. 